\title{
Does Education and Experience Matter in the Distribution of Wages in Nepal? A Quantile Regression Approach
}

\author{
Pujan Adhikari \\ Lecturer, Tribhuvan University, Nepal. \\ Kishor KC \\ Statistics Officer, Central Bureau of Statistic, Nepal. \\ Siddha Raj Bhatta \\ Deputy Director, Nepal Rastra Bank, Nepal.
}

\begin{abstract}
Labor market returns depend on the level of education as well as experience of the labors. Though education is argued to be the key determinant of wage rate, other factors such as the sector of employment, gender of the employee, marital status and work industry also matter. This paper investigates the returns from years of schooling and experience by examining the wage structure in formal, informal and agriculture sectors of Nepal. The Mincerion wage equation and quantile regression technique has been used to analyze such impact by utilizing the recent labor force survey data of Nepal. Our results show that wage returns are positively associated with schooling in all the three sectors. However, return to experience has negative association in case of agriculture sector. Furthermore, return to schooling has higher impact at higher quantile along with the distribution of wages in formal sector and informal sector. The maximum effect of education is 4 percent at 0.90 quantile in formal sector. An additional year of experience has high impact at lower-wage group in case of informal and formal sector. The effect varies from 9.2 percent at 0.1 quantile and 4.9 percent at 0.9 quantile in formal sector. The experience effect is higher at median (4.06 percent) in case of informal sector.
\end{abstract}

Key words: Returns to Schooling, Experiences, Wages, Quantile Regression JEL Codes: J24, J31

\section{INTRODUCTION}

It is often said that education, experience and skills impact the reward in the workplace. In many poor economies, education and labor market experience are the only human assets for a vast part of the labor force (Montenegr \& Patrinos, 2012). The years spent by an individual in school help develop skills and knowledge. Such skills acquired might have an impact on wage returns of the individual. The positive relationship between individual's schooling and his subsequent earnings may be understood to reflect the productivity augmenting effects of education (Mincer, 1974). Similarly, skill and knowledge acquired by "experience" is another factor of human capital that may influence wage returns of individuals. 
Empirical studies on returns to skills accumulated by years of schooling and experience in the labor market have been widely increased after Mincer (1974) originally proposed an empirical earnings function. This function has contributed to understand the relationship between investment in human capital and earnings.

Several studies have analyzed the effect of schooling years and experience on wage returns. For example, Chamberlin (1994) examines how the returns to schooling have changed from 1979 to 1987 by using the Current Population Survey of the USA. This paper uses a linear model of schooling, experience, and experience squared as prescribed by Mincer (1974). Looking separately at the young workers (0-9 years of experience) and peak earners (20-29 years of experience), the return (schooling coefficient) shows a tendency to increase for the young workers across the quantiles in 1987 while it is largely coming from the more experienced workers in 1979. Likewise, Schultz and Mwabu (1996) used quantile regression approach and suggested that the returns would be significant to extending primary education to the less educated and less able Africans and maximizing private returns to schooling would require expanding higher and secondary education for the African population in comparison to the Whites in South Africa.

Buchinsky (2001) used quantile regression to analyze changes in the returns to education for women in the US. By using the population survey data for the years 1968, 1973, 1979 and 1990, the results show that the returns to education increased enormously for the younger cohorts, but very little for the older cohorts. Montenegro (2001) looked at the gender wage differentials in the returns to education as well as experience and gender wage differential in the Chilean case. By using standard Mincerian wage function and quantile regression, the results from the study show systematic differences in the returns to education and experience by gender along with the conditional wage distribution.

Many studies are based on quantile regression technique to analyze the education, experience and wage return relationship. In this context, the estimator which minimizes the sum of absolute residuals is preferred (Koenker \& Bassett, 1978). In the Ordinary Least Squares method (OLS), average represents the overall distribution of wages. However, for survey data, median or some other quantile may truly represent distribution. Instead of focusing on the mean, it is quite natural to consider other aspects of the population distribution, such as the median or some other quantile (Chamberlin, 1994).

Even then, various studies have applied the OLS technique. For instance, Earle (2010) used Adult Literacy and Life Skills (ALL) survey data to look at the effect of literacy, 
qualifications and experience by using ordinary least squares in New Zealand. The results show that major benefits come from improved literacy in combination with gaining qualifications and similar result have been found in case of experience i.e. great opportunities into higher paid job comes from experience in combination with increased qualifications.

Wannakrairoj (2012) examined the relationship between education and experience on wages, especially the differences in urban and rural labor markets. The study based on Mincerian wage equation with labor force survey data found that education and experience have significant positive relationship with wages in both urban and rural labor markets in case of Thailand. Similarly, using the OLS technique, Schultz and Mwabu (1998) compared the effect of additional years of education with lower quality of education provided Africans and Whites in South Africa, and found that the percentage wage gains associated with additional years of primary, secondary, and higher education are substantially larger for the Africans than for the Whites in 1993.

In Nepalese context, only few studies have been carried out based on OLS technique. Risal and Gupta (2017) applied a multivariate regression model using data from Nepal Labor Force Survey, 2008. They found positive relationship of education and experience with their wages and estimated that 16.64 percent increment in wage with an increase in education and 11.75 percent increase in wage with increase in experience. In this context, Montenegro and Patrinos (2012) made comparable estimates of returns to schooling around the world. In case of Nepal, using Mincerian wage model and based on national household survey data, this study estimated that returns to an extra year of schooling is 8.4, 7.6 and 9.2 for 1998, 2008 and 2010 respectively.

Montenegro and Patrinos (2012) summarize the last 40 years' patterns (based on various researchers' study ${ }^{1}$ ) of estimated returns to schooling across the developing economies and present the consistent findings across the various surveys. The study concludes that private returns to schooling are generally positive and average rate of return to schooling is 10 percent a year.

A number of studies have examined wage structure focusing on the changes at different spectrum in the wage distribution. The studies have focused various issues such as gender differential in the returns to education and experiences (Montenegro

1 Researchers (Banerjee and Duflo (2005); Colclough, Gandhi Kingdon, and Patrinos (2010); Harmon, Oosterbeek, and Walker (2003); Psacharopoulos (1972), Psacharopoulos (1973), Psacharopoulos (1985), Psacharopoulos (1989), Psacharopoulos (1994); Psacharopoulos and Patrinos (2004), Psacharopoulos and Layard (2012)) have reported on the patterns of estimated returns to schooling across developing economies 
,2001; Addabbo, Favaro \& Magrini, 2007)), Women's return to education (Buchinsky (2001), return to investments in schooling (Montenegro \& Patrinos, 2012), labor market outcomes of skills and qualifications (Earle, 2010), higher education and wage inequality ( Lee, Shin \& Lee, 2015), wage returns to schooling and early work experiences ( Ashworth, Hotz, Maurel \& Ransom, 2018). Majority of the work in this area have focused on gender discrimination, labor wage of the economy, wage return dynamics, racial discrimination, wage inequality and other variety of social issues. However, the effect of education and experience on wage return in formal, informal and agriculture sector of the economy has still remained unexplored. In addition, change in wage structure is an important area of study in Nepal's case; however, relatively less attention has been paid to this issue. The structural change of the economy is shifting fundamentally after the adoption of liberalization policies. The economy is shifting from rural agriculture to service sector. The stagnant pattern of employment in the last few decades has changed and contribution of service sector is increasing. Since about 62 percent of the workers in Nepal work in informal sector, studying the determinants of wage structure in informal as well as formal sector is desirable to provide insights for the policy makers.

This paper is an attempt to examine the changes in the wage structure of labor arising from the investment in human capital, particularly education and experience, in formal, informal and agriculture sectors of Nepal. The Mincerion wage equation and quantile regression technique have been used to analyze such effect.

The remainder of the study is organized as follows: section II explains the methodology applied in this study, section III describes the data, section IV presents the empirical results and the last section concludes the study.

\section{METHODOLOGY}

The human capital earnings function developed by Mincer (1974) which is also known as "Mincerian Model", has been used to analyze the impact of education and experience on wage returns. The standard form of semi-log earnings function proposed by Mincer is,

In $\left(Y_{i}\right)=\beta\left(X_{i}\right)+u_{i}$

Where $\ln \left(Y_{i}\right)$ is the log of earnings or wages for individual $i, X_{i}$ is a vector that generally comprises schooling year or educational level and experience level. Many other control variables that may affect earnings are also included in this vector. $u_{i}$ is error term that represents unobserved variables. 
The functional form of equation (1) for our study is,

$\ln \left(\right.$ wage $\left._{\mathrm{i}}\right)=\beta_{0}+\beta_{1}$ educ $_{\mathrm{i}}+\beta_{2}$ exper $_{\mathrm{i}}+\beta_{3}\left(\text { exper }_{\mathrm{i}}\right)^{2}+\beta_{4}$ gender $+\beta_{5}$ marital $+\beta_{6}$ region $+\mathrm{u}_{\mathrm{i}} \cdot$.

Where, $\ln \left(\right.$ wage $\left._{\mathrm{i}}\right)$ is the natural log of the daily earnings of the $\mathrm{i}^{\text {th }}$ individual; educ is the years of schooling of $\mathrm{i}^{\text {th }}$ individual, exper is the years of experience of the $\mathrm{i}^{\text {th }}$ individual, $\operatorname{exper}_{i}{ }^{2}$ is the experience-squared, gender is dummy variable for male and female, marital is dummy variable for married and unmarried, region is dummy variable for rural and urban and $\mathrm{u}_{\mathrm{i}}$ is the error term reflecting unobserved variables.

This study examines relative earnings instead of the absolute. The time measures of investment and education is used instead of monetary measures (in Rs.) because data is available in time. Semi-log model (earning function in logs) is considered for these two reasons as suggested by Mincer. In this model, quality of education, ability and opportunity which affect the rate of returns has not considered.

Although, OLS is a traditional method used to estimate the Mincerian equation (Montenegro, 2001), we have used the quantile regression to estimate the Mincerian wage equation. It has been done for two reasons: first, the survey data are typically not homoscedastic; which makes OLS inefficient and the usual standard errors are incorrect (Wooldridge, 2005). In such a situation, presence of heteroskedasticity can be conventionally analyzed and displayed by estimating quantile regression (Deaton, 2015). Deaton further emphasizes on use of quantile regression while working with large-scale survey data because the median regression is more resistant to outliers than OLS. Second, quantile regression is effective to analyze regression for different quantile of the wage distribution in all three sectors: formal, informal and agriculture. It allows controlling whether the predictive power of a model changes at the different points of the conditional distribution (Furno, 2010).

The quantile regression model proposed by Koenker and Bassett (1978) is:

$Y_{i}=X_{i} \beta_{q}+u_{i}$

Where $\beta_{\mathrm{q}}$ is the vector of an unknown parameter associated with the $\mathrm{q}^{\text {th }}$ quantile.

The expanded expression of equation (3) is :

$\phi_{q}=\sum_{y_{i}}^{N} \geq x_{i} \beta q\left|\left(y_{i}-x_{i} \beta_{q}\right)\right|+\sum_{y_{i}<x_{i} \beta}^{N}(1-q)\left|\mathrm{y}_{i}-x_{i} \beta_{q}\right|$ 
The quantile regression estimates for the $\mathrm{q}^{\text {th }}$ quantile can be obtained from the above (iv) minimization problem. The coefficient $\beta_{\mathrm{q}}$ is associated with $\mathrm{q}^{\text {th }}$ quantile of the dependent variable.

The conditional expression for the quantile regression model for this study can be expressed as:

$Q_{\log (\text { wage })}(q \mid x)=\beta_{0}+\beta_{1}$ educ $_{\mathrm{i}}+\beta_{2}$ exper $_{\mathrm{i}}+\beta_{3}\left(\text { exper }_{\mathrm{i}}\right)^{2}+\beta_{4}$ gender $+\beta_{5}$ marital $+\beta_{6}$ region $+\mathrm{u}_{\mathrm{i}} \ldots \ldots$

\section{DATA}

Nepal Labor Force Survey $(2017 / 18)^{2}$ data produced by the Central Bureau of Statistics has been used for the analysis. Nepal Labor Force Survey (NLFS III) covered a nationally representative sample of 18000 households from 900 Primary Sampling Units (PSUs) distributed between urban and rural areas. In this study, the observation consists of fifteen years and above age employees who satisfy the following criteria: (a) work in private financial business firm, private non-financial institutions, non-profit institutions and other institutions. But those who work in government, state-owned enterprises and international organizations/foreign embassy are not included (b) mode of payment is cash. Our earnings measure is daily wage.

These criteria reduce the observations from 77,638 to 6,526 . We segregate the observations into formal, informal and agriculture sector for our analysis using the following criteria, which is based on NLFS (2017/18).

\section{Formal sector}

- Existing name, location and type of organization should be government, stateowned enterprises and international organization/foreign embassy.

- Existing name or without name and type of enterprise/business should be an incorporated company.

- Existing name or without name and the enterprise/business should have registered with relevant authority.

2 The survey is carried out by Central Bureau of Statistics (CBS) from July 2017 to June 2018 and is the third round of a multi topic national labor force survey which followed the new concepts and definitions (recommendation of 19th ICLS). NLFS III provide a large number of data set about employment status, characteristics of job/business activity, working time, employment related income including demographic characteristics of household members and housing characteristics of households. 


\section{Informal sector}

- Those organizations which do not come into the criteria of formal sector are considered as informal sector.

\section{Agriculture Sector}

- Those organizations involved with agriculture, forest and fishing activities as defined by the International Standard Industrial Classification of all economic activities (ISIC) Revision-4 are considered as agriculture sector. Such organizations might be formal or informal.

Based on the above definition, the sample sizes for agriculture, informal and formal sectors stand at 1020, 4442 and 2084 observations respectively.

For years of schooling, we converted the highest level of education completed by the individuals into years of schooling. For example, an individual who completed $8^{\text {th }}$ grade is considered to have 8 years of schooling. Similarly, years of experience at current workplace is considered as experience years. The survey has provided information of experience in range of years. We considered the minimum value of range as experience year. We adjusted the raw data by adding 0.5 years for the log wage equation to address the zero values.

\section{RESULT}

The estimation has been carried out for the three sectors: formal, informal and agriculture. The results from the estimated Mincerian wage equation have been presented in Table 1 to Table 3. The results shows both mean and quantile estimates for the sector. However, we consider various quintiles of the log wage distribution instead of focusing on average estimates. The values enclosed within brackets below the coefficients represent the $t$-value and $p$-value respectively. Our main objective is to estimate the effect of schooling years and years of experience of individuals on their wage rate in all three sectors separately.

Chart 1, 2 and 3 Shows whether the quantile coefficients are significantly difference from OLS estimates. This justified the use of quantile regression due to presence of heteroskedasticity. The vertical axis measures the returns to education and experience coefficient, the horizontal axis depicts the quantiles of the conditional wage distribution for all three sectors. The horizontal line plots the OLS estimates. The dot line represents the $95 \%$ confidence interval around it. The shaded region around the dot curve is confidence interval around the quantile. In agriculture sector, for the low and high quantiles, there is significance difference from the OLS in case of experience but no 
difference in wage distribution in case of education. Similarly, in informal sector, there is significance difference about the OLS in low quantiles in case education and experience. In formal sector, for the low and high quantiles, there is significant difference from OLS for education but OLS estimates differ significantly only in low quantiles in case of experience.

In all sector, the distribution of wage between $20^{\text {th }}$ to $80^{\text {th }}$ quantile, quantile estimates of education and experience do not have significance difference to OLS estimates. Quantile estimates are significantly differing in lower and higher wage group from OLS estimates.

Chart 1: Agriculture Sector
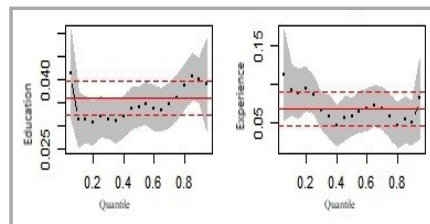

Chart 2: Informal Sector
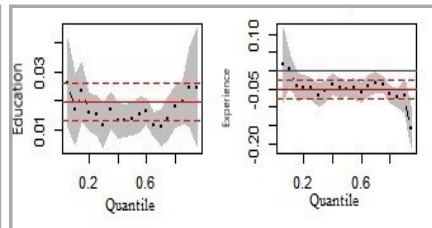

Chart 3: Formal Sector

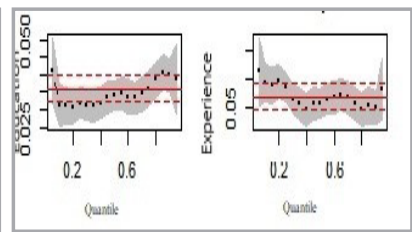

Table 1 shows how schooling and experience affect the various quantiles $(0.1,0.25,0.50$, $0.75,0.90)$ of the wage in agriculture sector. The return to schooling across the quantiles ranges from 1.38 percent at the 0.50 quantile to 2.4 percent at 0.90 quantile. However, there is no significant difference between coefficients from 0.1 quantile to 0.9 quaintile. Similarly, returns to experience has negative effect along with the distribution of wages. Moreover, OLS results also show the negative associations between the variables. This negative return to experience is generally against the theoretical expectations and may be due to negative marginal productivity of labor in agriculture sector in Nepal. 
Table 1: Agriculture Sector

\begin{tabular}{|c|c|c|c|c|c|c|}
\hline \multirow{2}{*}{ Variable } & \multicolumn{5}{|c|}{ Quantile } & \multirow{2}{*}{ OLS } \\
\hline & 0.10 & 0.25 & 0.50 & 0.75 & 0.90 & \\
\hline \multirow{3}{*}{ educ } & 0.0169 & 0.0152 & 0.0138 & 0.01389 & 0.02466 & 0.0195 \\
\hline & $(2.3652)$ & (3.6822) & $(4.20587)$ & $(3.20247)$ & $(3.04528)$ & $(4.999)$ \\
\hline & $(0.0182)^{* *}$ & $(0.0002)^{* * *}$ & $(0.00003)^{* * *}$ & $(0.00140)^{* * *}$ & $(0.00238)^{* * *}$ & $(6.78 \mathrm{e}-07)^{* * *}$ \\
\hline \multirow{3}{*}{ exper } & 0.0041 & -0.0493 & -0.05094 & -0.03950 & -0.07074 & -0.0520 \\
\hline & $(0.1531)$ & $(-2.8624)$ & $(-4.35653)$ & $(-2.85473)$ & $(-2.63526)$ & $(-3.176)$ \\
\hline & $(0.8783)$ & $(0.0043)^{* * *}$ & $(0.00001)^{* * *}$ & $(0.00439)^{* *}$ & $(0.00853)^{* *}$ & $(0.00154)^{* * *}$ \\
\hline \multirow{3}{*}{$\operatorname{exper}^{\wedge} 2$} & -0.0007 & 0.0031 & 0.00335 & 0.00282 & 0.00581 & 0.0037 \\
\hline & $(-0.2778)$ & $(2.0148)$ & $(3.27555)$ & $(2.71367)$ & $(2.51588)$ & (2.563) \\
\hline & $(0.7812)$ & $(0.0442)^{* *}$ & $(0.00109)^{* * *}$ & $(0.00677)^{* * *}$ & $(0.01203)^{* *}$ & $(0.01052)^{* *}$ \\
\hline \multirow{3}{*}{ gender } & 0.2231 & 0.2385 & 0.28768 & 0.25136 & 0.25043 & 0.2676 \\
\hline & $(4.5569)$ & $(7.3345)$ & $(13.06736)$ & $(12.44676)$ & $(4.49648)$ & (9.796) \\
\hline & $(0.0000)^{* * *}$ & $(0.0000)^{* * *}$ & $(0.00000)^{* * *}$ & $(0.0000)^{* * *}$ & $(0.00001)^{* * *}$ & $(<2 \mathrm{e}-16)^{* * *}$ \\
\hline \multirow{3}{*}{ marital } & 0.0793 & -0.0478 & -0.10575 & -0.15282 & -0.17346 & -0.1144 \\
\hline & $(1.3414)$ & $(-1.2493)$ & $(-3.53902)$ & $(-3.42663$ & $(-1.52108)$ & $(-2.476)$ \\
\hline & $(0.1801)$ & $(0.2119)$ & $(0.00042)^{* * *}$ & $(0.00064)^{* * *}$ & $(0.12855)$ & $(-0.01343)^{* *}$ \\
\hline \multirow{3}{*}{ region } & 0.0704 & -0.0106 & -0.01341 & -0.02821 & -0.0681 & -0.0063 \\
\hline & $(0.9969)$ & $(-0.2971$ & $(-0.61534)$ & $(-1.41758)$ & $(-1.21271)$ & $(-0.230)$ \\
\hline & $(0.3190)$ & $(0.7664)$ & $(0.53847)$ & $(0.15662)$ & $(0.22552)$ & $(-0.81842)$ \\
\hline \multirow{3}{*}{ Intercept } & 4.8448 & 5.4662 & 5.70714 & 6.01788 & 6.29544 & 5.8373 \\
\hline & $(29.7270)$ & $(58.3244)$ & $(91.88162)$ & $(73.9972)$ & $(34.77568)$ & $(69.869)$ \\
\hline & $(0.0000)^{* * *}$ & $(0.0000)^{* * *}$ & $(0.0000)^{* * *}$ & $(0.0000)^{* * *}$ & $(0.0000)^{* * *}$ & $(<2 e-16)^{* * *}$ \\
\hline
\end{tabular}

Source: Authors

Note: The values enclosed within brackets below the row of coefficients of variable represent the $\mathrm{t}$ value and p-value respectively. ${ }^{*},{ }^{* *},{ }^{* * *}$ indicates the significance of coefficient at 10 percent, 5 percent and 1 percent level significance.

Table 2 shows the effect of schooling and experience along the distribution of dependent variable in formal sector. The quantile estimates for returns to schooling are 3.1 percent, 3.25 percent, 3.41 percent, 3.60 percent and 4 percent for $0.1,0.25,0.50$, 0.75 , and 0.90 respectively. In table 4 , ANOVA test result shows the coefficients along the various quantiles have significant differences. This justifies the use of quantile regression technique in this study. The same estimate when using OLS estimates is 3.6 percent. Thus, returns to schooling shows a tendency of increasing returns along the 
quantiles and high returns for high wage groups in formal sector. Similarly, opposite tendency has been observed in case of returns to experience, ranging from 9.2 percent at lower wage groups and 4.9 percent at 0.90 quantiles. The effect is high at lower quantile. For this case, the OLS estimate is 6.8 percent.

Table 2: Formal Sector

\begin{tabular}{|c|c|c|c|c|c|c|}
\hline \multirow{2}{*}{ Variable } & \multicolumn{5}{|c|}{ Quantile } & \multirow{2}{*}{ OLS } \\
\hline & 0.10 & 0.25 & 0.50 & 0.75 & 0.90 & \\
\hline \multirow[t]{3}{*}{ educ } & 0.03117 & 0.0320 & 0.0341 & 0.0360 & 0.0400 & 0.0360 \\
\hline & $(8.38389)$ & $(12.0663)$ & $(12.9591)$ & $(12.0681)$ & $(13.8877)$ & $(15.4300)$ \\
\hline & $(0.0000)^{* * *}$ & $(0.0000)^{* * *}$ & $(0.0000)^{* * *}$ & $(0.0000)^{* * *}$ & $(0.0000)^{* * *}$ & $(<2 \mathrm{e}-16)^{* * *}$ \\
\hline \multirow[t]{3}{*}{ exper } & 0.09225 & 0.0858 & 0.0581 & 0.0572 & 0.0498 & 0.0687 \\
\hline & $(4.60718)$ & $(5.7126$ & $(3.8414$ & $(3.3190$ & $(2.8836)$ & $(5.1670)$ \\
\hline & $(0.0000)^{* * *}$ & $(0.0000)^{* * *}$ & $(0.0001)^{* * *}$ & $(0.0009)^{* * *}$ & $(0.0040)^{* * *}$ & $(0.0000)^{* * * *}$ \\
\hline \multirow[t]{3}{*}{$\operatorname{exper}^{\wedge} 2$} & -0.00512 & -0.0047 & -0.0027 & -0.0026 & -0.0024 & -0.0032 \\
\hline & $(-3.03025)$ & $(-3.4613)$ & $(-1.9914)$ & $(-1.7302)$ & $(-1.6485)$ & $(-2.7850)$ \\
\hline & $(0.0000)^{* * *}$ & $(0.0006)^{* * *}$ & $(0.0466)^{* *}$ & $(0.0838)^{*}$ & $(0.0994)$ & $(0.0054)^{* *}$ \\
\hline \multirow[t]{3}{*}{ gender } & 0.38974 & 0.4167 & 0.3852 & 0.3141 & 0.2842 & 0.3753 \\
\hline & $(9.23351)$ & $(14.2322)$ & $(12.4321)$ & $(9.0471)$ & $(8.3297)$ & $(15.2850)$ \\
\hline & $(0.0000)^{* * *}$ & $(0.0000)^{* * *}$ & $(0.0000)^{* * *}$ & $(0.0000)^{* * *}$ & $(0.0000)^{* * *}$ & $(<2 \mathrm{e}-16)^{* * *}$ \\
\hline \multirow[t]{3}{*}{ marital } & -0.19804 & -0.2214 & -0.1749 & -0.1423 & -0.1609 & -0.1685 \\
\hline & $(-5.01764)$ & $(-6.8229)$ & $(-5.0634)$ & $(-4.1408)$ & $(-3.5491)$ & $(-6.2710)$ \\
\hline & $(0.0000)^{* * *}$ & $(0.0000)^{* * *}$ & $(0.0000)^{* * *}$ & $(0.0000)^{* * *}$ & $(0.0004)^{* * *}$ & $(0.0000)^{* * *}$ \\
\hline \multirow[t]{3}{*}{ region } & 0.11757 & 0.0758 & 0.0177 & 0.0401 & -0.0212 & 0.0502 \\
\hline & $(2.51269)$ & $(1.7380)$ & $(0.5401)$ & $(1.0201)$ & $(-0.6762)$ & $(1.7850)$ \\
\hline & $(0.01206)^{* *}$ & $(0.0824)^{*}$ & $(0.5892)$ & $(0.3078)$ & $(0.4990)$ & $(0.0744)^{*}$ \\
\hline \multirow[t]{3}{*}{ Intercept } & 4.34121 & 4.6783 & 5.1354 & 5.4926 & 5.9393 & 5.0464 \\
\hline & $(30.82497)$ & $(40.6136)$ & $(51.4544)$ & $(47.1076)$ & (56.3278 & $(60.8380)$ \\
\hline & $(0.0000)^{* * *}$ & $(0.0000)^{* * *}$ & $(0.0000)^{* * *}$ & $(0.0000)^{* * *}$ & $(0.0000)^{* * *}$ & $(<2 \mathrm{e}-16)^{* * *}$ \\
\hline
\end{tabular}

Source: Authors

Note: The values enclosed within brackets below the row of coefficients of variable represent the $\mathrm{t}$ value and $\mathrm{p}$-value respectively. ${ }^{*},{ }^{* *},{ }^{* *}$ indicates the significance of coefficient at 10 percent, 5 percent and 1 percent level significance.

The quantile returns based on the informal sector earnings data are shown in table 3. In informal sector, the schooling effect across the lower to higher quantiles is 0.9 percent, 1.1 percent, 1.4 percent, 1.2 percent and 1.3 percent. The mean effect is 1.3 percent. 


\section{Table 3: Informal Sector}

\begin{tabular}{|c|c|c|c|c|c|c|}
\hline \multirow{2}{*}{ Variable } & \multicolumn{5}{|c|}{ Quantile } & \multirow{2}{*}{ OLS } \\
\hline & 0.10 & 0.25 & 0.50 & 0.75 & 0.90 & \\
\hline \multirow[t]{3}{*}{ educ } & 0.00949 & 0.0111 & 0.0148 & 0.0125 & 0.0130 & 0.013741 \\
\hline & (3.45792) & $(4.8531)$ & (6.9073) & (6.6493) & $(5.7837)$ & $(7.832)$ \\
\hline & $(0.0006)^{* * *}$ & $(0.0000)^{* * *}$ & $(0.0000)^{* * *}$ & $(0.0000)^{* * *}$ & $(0.0000)^{* * *}$ & $(0.0000)^{* * *}$ \\
\hline \multirow[t]{3}{*}{ exper } & 0.03197 & 0.0313 & 0.0406 & 0.0266 & 0.0292 & 0.029828 \\
\hline & $(2.86697)$ & $(2.7812)$ & $(3.9507)$ & $(3.0172)$ & $(2.7330)$ & (3.714) \\
\hline & $(0.0042)^{* * *}$ & $(0.0054)^{* * *}$ & $(0.0001)^{* * *}$ & $(0.0026)^{* * *}$ & $(0.0063)^{* * *}$ & $(0.0002)^{* * *}$ \\
\hline \multirow[t]{3}{*}{ exper $^{\wedge} 2$} & -0.00248 & -0.0018 & -0.0024 & -0.0016 & -0.0019 & -0.00201 \\
\hline & $(-2.33192)$ & $(-1.8370)$ & $(-2.6097)$ & $(-2.1947)$ & $(-2.0908)$ & $(-2.873)$ \\
\hline & $(0.0198)^{* *}$ & $(0.0663)^{*}$ & $(0.0091)^{* *}$ & $(0.0282)^{* *}$ & $(0.0366)^{* *}$ & $(0.0041)^{* * *}$ \\
\hline \multirow[t]{3}{*}{ gender } & 0.53985 & 0.4618 & 0.4312 & 0.4717 & 0.3738 & 0.455486 \\
\hline & $(24.01507)$ & $(19.4480)$ & $(21.1072)$ & (20.9075) & (13.6156) & (27.793) \\
\hline & $(0.0000)^{* * *}$ & $(0.0000)^{* * *}$ & $(0.0000)^{* * *}$ & $(0.0000)^{* * *}$ & $(0.0000)^{* * *}$ & $(<2 \mathrm{e}-16)^{* * *}$ \\
\hline \multirow[t]{3}{*}{ marital } & -0.21365 & -0.1631 & -0.1696 & -0.2019 & -0.1300 & -0.1979 \\
\hline & $(-5.70148)$ & $(-6.5243)$ & $(-8.7484)$ & $(-9.1748)$ & $(-3.0566)$ & $(-10.039)$ \\
\hline & $(0.0000)^{* * *}$ & $(0.0000)^{* * *}$ & $(0.0000)^{* * *}$ & $(0.0000)^{* * *}$ & $(0.0023)^{* * *}$ & $(<2 \mathrm{e}-16)^{* * *}$ \\
\hline \multirow[t]{3}{*}{ region } & -0.0584 & -0.0628 & -0.0604 & -0.0625 & -0.0715 & -0.05893 \\
\hline & $(-2.23527)$ & $(-3.3783)$ & $(-3.4428)$ & $(-4.4299)$ & $(-4.3159)$ & $(-4.312)$ \\
\hline & $\begin{array}{r}(2.55 \mathrm{E}- \\
02)^{* * *}\end{array}$ & $(0.0007)^{* * *}$ & $(0.0006)^{* * *}$ & $(0.0000)^{* * *}$ & $(0.0000)^{* * *}$ & $\begin{array}{r}(1.66 \mathrm{E}- \\
05)^{* * *} \\
\end{array}$ \\
\hline \multirow[t]{3}{*}{ Intercept } & 4.98341 & 5.3357 & 5.6153 & 5.9006 & 6.2501 & 5.622208 \\
\hline & $(69.24038)$ & $(87.1880)$ & (101.4653) & (105.7875) & $(83.2961)$ & (126.915) \\
\hline & $(0.0000)^{* * *}$ & $(0.0000)^{* * *}$ & $(0.0000)^{* * *}$ & $(0.0000)^{* * *}$ & $(0.0000)^{* * *}$ & $(<2 \mathrm{e}-16)^{* * *}$ \\
\hline
\end{tabular}

Source: Authors

Note: The values enclosed within brackets below the row of coefficients of variable represent the $t$ value and p-value respectively. ${ }^{*},{ }^{* * * *}$ indicates the significance of coefficient at 10 percent, 5 percent and 1 percent level significance. 
This shows the low positive effect of additional years of schooling and minimum variation in magnitude of effect along the various wage groups. Similarly, the experience effect at median is highest (4.06 percent) than at other distributions. This effect is low (2.92 percent) for high wage group. The coefficients along the quantiles are significantly different. For this case, the OLS estimate is 2.9 percent. In Table 4, The ANOVA test shows the coefficients along the various quantiles have significant differences

Table 4: ANOVA

\begin{tabular}{|l|l|l|l|l|l|l|l|l|}
\hline \multicolumn{3}{|c|}{ Agriculture Sector } & \multicolumn{3}{c|}{ Formal Sector } & \multicolumn{3}{c|}{ Informal Sector } \\
\hline $\begin{array}{l}\text { Between } \\
\text { the } \\
\text { Quantile }\end{array}$ & $\begin{array}{l}\text { F } \\
\text { value }\end{array}$ & P value & $\begin{array}{l}\text { Between } \\
\text { the } \\
\text { Quantile }\end{array}$ & $\begin{array}{l}\text { F } \\
\text { value }\end{array}$ & P value & $\begin{array}{l}\text { Between } \\
\text { the } \\
\text { Quantile }\end{array}$ & $\begin{array}{l}\text { F } \\
\text { value }\end{array}$ & P value \\
\hline 10th-50th & 3.7111 & $0.0011^{* *}$ & 10th-50th & 1.6443 & 0.1307 & 10 th-50th & 4.2679 & $0.0002^{* * *}$ \\
\hline 10th-90th & 1.746 & 0.1066 & 10th-90th & 3.8183 & $0.0008^{* * *}$ & 10th-90th & 4.4722 & $0.0001^{* * *}$ \\
\hline 50th-90th & 0.9214 & 0.4783 & 50th-90th & 2.4883 & $0.02096^{*}$ & 50 th-90th & 2.2365 & $0.0369^{*}$ \\
\hline
\end{tabular}

Source: Authors

Note: ${ }^{*}{ }^{* *},{ }^{* *}$ indicates the significance of coefficient along the quantile at 10 percent, 5 percent and 1 percent level significance.

\section{DISCUSSION AND CONCLUSIONS}

This paper examines the sectoral differences in returns to education and experience along with the conditional wage distribution in Case of Nepal by using the recent labor force survey data. The results from the study provide several important conclusions.

First, for all sectors, education has a positive impact and increasing tendency in wage returns as we move from the lower to a higher range of conditional distribution. This finding is in line with Patrinios, Fishbein and Giovanali (2007) in case of Argentina, Widyanti (2018) for Indonesia, Marteins and Pereira (2003), Tansel and Bircan (2011) for Turkey, and Mitra and Tout (2017) for India.

Second, the schooling effect is high in formal sector as compared to other sectors and maximum of 4 percent at higher wage group ( 0.9 quantile) in formal sector. One reason for the low effect of schooling in agriculture as well as informal sector may be the fact that wages in agricultural sector depends on other factors such as structural rigidities leading to low productivity and payments of wages in kind rather than cash. 
Third, additional year of experience results negative returns in agriculture whereas positive impact in both formal and informal sector. This is consistent with the case of India as pointed by Mitra and Tout (2017).

Fourth, lower wage groups have higher effect of additional year of experience in formal and informal sector. The responsiveness of years of experience is highest at 9.2 percent at 0.1 quantile group in formal sector.

These findings can be useful for the policy makers to design education programs so as to increase the productivity and per capita income of the workers. The sectoral and wage group differences in the returns to education may further help understand the wage inequality and devise proper policy actions to address the issue.

One caveat of this paper is that it ignores the quality as well as type of education which could have significant impact on labor market returns. We could not do so as the labor force survey does not have information on the type of education such as general, technical and vocational. It might be an interesting issue for future studies in this area. Furthermore, including the workers who receive wages in kind might help portray the true return to education in agricultural as well as informal sector.

\section{REFERENCES}

Addabbo, T., Favaro, D., \& Magrini, S. (2007). The distribution of the gender wage gap in italy: Does education matter? Recent Center for Economic Research.

Ashworth, J., Hotz, J., Maurel, A., \& Ransom, T. (2018). Changes across cohorts in wage returns to schooling and early work experiences. Economic Research Initiatives at Duke.

Buchinsky, M. (2001). Quantile regression with sample selection: estimating women's return to education in the U.S. Emperical Economics, 26,87-113.

Chamberlin, G. (1994). Quantile regression, censoring, and the structure of wages. Proceedings of the Econometrics Society, Barcelona,Spain (pp. 171-209). New York: Cambridge University Press.

Deaton, A. (2018). The analysis of household surveys. World Bank Group.

Earle, D. (2010). Skills, qualifications, experience and the distribution of wages. The Tertiary Education Occasional Papers, Ministry of Education, NewZealand.

Furno, M. (2010). Goodness of fit and misspecification in quantile regression. Journal of Educational and Behavioral Statistics, 36 (1),105-131.

Koenker, R., \& Bassett, G. (1978). Regressions quantiles. Econometrica, 46, 33-35. 
Lee, Y., Shin, Y., \& Lee, D. (2015). The option value of human capital: higher education and wage inequality. Massachusetts: National Bureau of Economic Research.

Martins, S., \& Pereira, T. (2003). Does education reduce wage inequality? Quantile regression evidence from 16 countires. Labour Economics, 11, 355-371.

Mincer, J. (1974). Schooling, experience and earnings. New York: The National Bureau of Economic Research.

Mitra, A., \& Rout, S. (2017). Returns to education in Odisha: A comparative study between agriculture and industrial workers. Manpower Journal, 42-61.

Montenegro, E., \& Patrinos, A. (2014). Comparable estimates of returns to schooling around the world. World Bank Group.

Montengro, C. (2001). Wage distribution in chile: Does gender matter? A quantile regression approach. Policy Research On Gender and Development, World Bank.

Mwabu, G., \& Schultz, P. T. (1996). Education returns across quantiles of the wage fuction: Alternative explanations for returns to education by the race in South Africa . The American Economic Review, 86(2), 335-339.

Patrinos, A., Fiszbein, A., \& Giovagnoli, I. P. (2007). Estimating the returns to education in argentina using quantile regression analysis: 1992-2002. Economica, 53, 5372.

Risal, G. H., \& Gupata, P. (2017). Evaluating the impact of education on earnings in Nepal. Delhi Business Review.

Schultz, P., \& Mwabu, G. (1998, February). Wage premia for education and location, by gender and race in South Africa. Center Discussion Paper No. 785. Economic Growth Center, Yale University .

Tansel, A., \& Bircan, F. (2011). Wage inequality and returns to education in Turkey: a quantile regression analysis technique. IZA Discussion Papers, No. 5417. Institute for the Study of Labor (IZA), Bonn.

Wannakrairoj, W. (2013). The effect of education and experience on wages: The case study of Thailand in 2012. South Asian Journal of Economics, 1(1), 27-48.

Widyanti, R.D. (2018). Wage inequality and return to education in Indonesia: Quantile regression analysis. Jurnal Ilmu Ekonomi, 7(1),27-44.

Wooldridge, M. J. (2013). Introductory econometrics. Delhi: Cengage Learning India Privated Limited. 